\title{
Adaptation to Climate Change: The Case of Uganda
}

\author{
Margaret Magumba
}

\begin{abstract}
Uganda, like several other countries, awaits a significant change in its climate and anticipates adverse effects as a result of the change. Some of the anticipated effects include: drought; agricultural destruction; transport encumbrances and destruction of lives and property due to floods; reduction in biomass and hydroelectric energy production; increase in water-borne diseases due to floods and poor sanitation; increase in Malaria incidence; social discomfort due to higher temperatures and, spill-over economic effects like reduced donor aid. All these events combined will adversely affect the country's economy if necessary action is not taken in time. The country has documented a number measures to help it adapt to future climate change but practical efforts to implement these measures are hardly visible. This paper proposes that to be on the safe side, among other strategies, the country's way forward should include: modernization of agriculture; adoption of drought insurance schemes; economic diversification; construction of roads with adequate drainage; use of oil revenue to extend piped water supply to the country's entire population; intensification of domestic revenue mobilization to reduce dependence on donor aid; gradual substitution of biomass and hydroelectric energy usage with oil energy usage and, incorporation of climate change coping mechanisms in people's lifestyles. It is of absolute importance that the country takes the necessary precautionary action in time.
\end{abstract}

Keywords: climate change, adaptation, sustainable development, drought, floods, agriculture modernisation DOI: $10.7176 / \mathrm{JESD} / 10-6-01$

Publication date:March $31^{\text {st }} 2019$

\section{Introduction}

1.1 Overview

Several studies and statistics indicate that adverse climate change is an unavoidable impeding crisis awaiting the world in a few years to come. Many argue that it's not a matter of if, but when, the world will experience catastrophic climate change. In fact, several regions of the world are already experiencing a significant amount of it, and consequently bearing the burden that follows. For several reasons, some of which are briefly discussed in this paper, it is unlikely that a reversal of this climatic prediction will occur. Several countries have therefore resorted to devising means of adapting to the impending challenges, while others have turned a blind eye, considering climate change as yet another modern day fictitious story.

This paper examines Uganda's efforts towards adaptation to climatic change, citing likely effects of its occurrence, and suggesting a way forward to ensure the country's immunity against its predicted adverse effects. The main assertion of the paper is that Uganda is well-aware of the forthcoming effects of climate change, and has consequently documented strategies to overcome them, but has hardly made any practical efforts to shield itself against them. Among other proposals, the paper suggests that in order for the country to successfully adapt to climatic changes, which will undoubtedly affect its socioeconomic wellbeing, it should urgently make deliberate efforts to modernize agriculture, diversify its economy, diversify energy sourcing, and build infrastructure that is tailored to withstand the projected climate of the country.

\subsection{Context}

Today's drastic climatic change and its prospects have mainly been caused by contemporary economic activities, mostly carried out in developed economies. Modern-day science asserts that increased pollution/ emission of greenhouse gases has led to global warming and depletion of the ozone layer, leading to diverse climatic changes worldwide. Unfortunately, even though low income countries like Uganda haven't had much to do with the causation, they equally share the burden of the consequences, which may be adverse in the future if no steps are taken to curtail them.

Certainly, economies worldwide will not be able to stop the predicted fate of climatic change; first, because today's way of life is synonymous with its causes and, needless to mention, it's close to impossible to hastily change an entire universe's way of life; second, because there is a free rider effect in countries' efforts towards reducing its causes. Every country would like to see other countries reduce climate-degrading activities for the benefit of everyone, but no country is individually willing to sacrifice its currently beneficial economic activities for the good of the world at large. Hence, the only option is to devise means of adaptation to the anticipated challenges. 


\section{Summary of Uganda's Current Climatic State, and its Predicted Changes}

\subsection{Uganda's Current Climatic State}

Uganda is a tropical country with humid equatorial climate. It typically experiences two types of seasons in a year i.e. the dry season and the wet/rainy season. The dry seasons are generally hotter with little or no rainfall, and the wet seasons are cooler with abundant rainfall. According to Irish Aid (2017), the country experiences average near surface temperatures of $21 \mathrm{oC}$, with a minimum of $15 \mathrm{oC}$ that usually occurs in July, and a maximum of $30 \mathrm{oC}$ that usually occurs in February. Seasonal variations are vast across the country, with higher temperatures in the northern region and cooler temperatures in the southern region. Some regions experience two wet seasons in a year, and others experience one prolonged wet season annually. Agricultural/ farming cycles revolve around the climatic seasons in each region.

Contrary to some views, experience has proved that climate change claims are not myths. "Historic trends show that the climate is changing in Uganda. Average annual temperatures increased noticeably by $1.3^{\circ} \mathrm{C}$ between 1960 and 2010, with the largest increase occurring during January and February. The frequency of hot days in the country increased significantly (by 20\%) between 1960 and 2003" (Future Climate for Africa [FCFA], 2016). Indeed, any ordinary Ugandan that has lived in the country for the last twenty years or more, would undoubtedly testify that there is a significant surge in the January-February heat waves.

\subsection{Predicted Climatic Changes in Uganda}

Irish Aid (2017) projects that temperature increments in Uganda will range between $+2 \mathrm{oC}$ and $+2.5 \mathrm{oC}$ in the next fifty years, and $+2.5 \mathrm{oC}$ and $+4.5 \mathrm{oC}$ in the next eighty years. FCFA (2016) indicates that the temperature increments will be accompanied by longer dry seasons and heavier rains during wet seasons, and further states that "some models project an increase of as much as 43\%" (FCFA, 2016) in rainfall, though this projection is claimed with less certainty. What is undisputed though, is the fact that rainfall will increase significantly in the wet seasons and reduce during the prolonged dry seasons. The combination of these two predictions implies undesirable results of floods, landslides and drought during the different seasons of the year. This would result in agricultural destruction and famine, ultimately crippling the economy, if proper action isn't taken ahead of time.

\section{Anticipated Effects of Climate Change on Uganda}

\subsection{Water-Related Effects}

The importance of water can not be over-emphasized. "Surface and groundwater resources play a major role in [Uganda's] domestic water supply, watering livestock, industrial operations, hydropower generation, agriculture, marine transport, fisheries, waste discharge, tourism, and environmental conservation" (Nsubuga et al, 2014).

Prolonged dry seasons in Uganda would culminate in drought and adversely affect the country's predominantly agricultural economy. Drought greatly reduces crop yield and negatively affects animal husbandry. Besides the obvious negative economic implications of drought on an agricultural economy, many Ugandans entirely depend on their agricultural yields for day to day survival and, unfortunately, drought could easily cost them their lives.

Less rainfall in the dry seasons would lower the level of the earth's water table. In poor countries where a significant portion of the population depends entirely on rainfall harvests, boreholes, springs or shallow wells for their water supply, this could mean the difference between life and death, during dry seasons. In Uganda, " $61 \%$ of the country's water is from a ground water source, accessed from springs and boreholes around Lake Victoria and south-western Uganda" (Nsubuga, 2014). Low ground water levels cause boreholes, springs and wells to dry up. If this plays out, several Ugandans will experience severe water scarcity, and will lack access to water for even the most basic of needs; drinking.

Conversely, increased heavy rains during the wet seasons would lead to destruction of crops, property and lives, as a result of flooding. From an agricultural standpoint, very heavy rains are equally as destructive as drought. Both extremes destroy crop and animal life. Undoubtedly, amplified tropical storms would lead to famine and a significant decline in Uganda's GDP, due to the damage imparted on the agricultural sector. Additionally, floods would destruct other economic activities through incapacitating the transport system. As a matter of fact, Uganda has already started experiencing this challenge today. Heavy rainfall causes roads in the central business district to flood, paralyzing economic activity during a significant portion of the wet seasons. Time is bound to make this adversity worse. 
Flooded roads after heavy downpours in Kampala, Uganda's capital city and main business hub

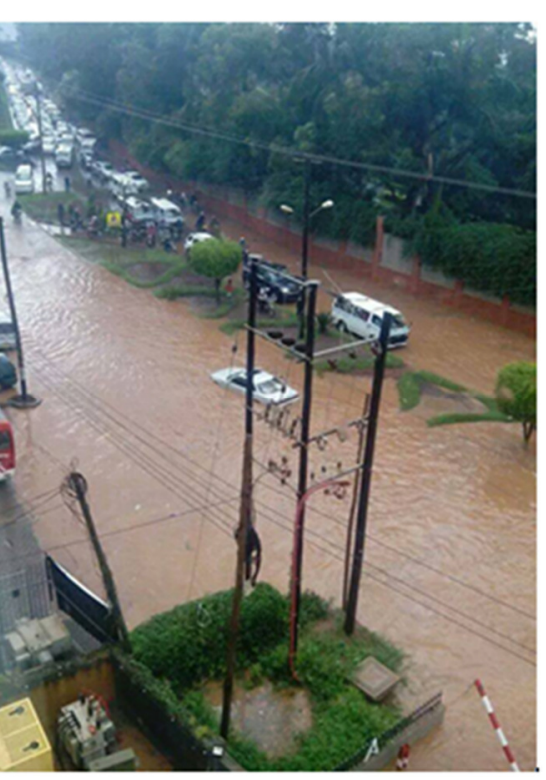

\subsection{Energy-Related Effects}

According to Irish Aid (2017), approximately $93 \%$ of Uganda's energy needs are met by use of biomass. Climate change poses a threat of increased forest fires, which would destroy a big percentage of the biomass that the country largely depends on. This would leave the country in a state of heightened energy-shortage.

Climate change also poses a threat of substantial reduction of water volumes in Uganda's rivers and lakes, due to rain scarcity and increased evaporation during the long dry seasons. This would obstruct sufficient generation of hydro-electricity in the country. Even though hydro-electricity power only accounts for $1 \%$ of Uganda's total energy use (Irish Aid, 2017), it is the backbone of contemporary economic activities like manufacturing and ICT in the country; hence, its importance should not be underplayed. Additionally, Uganda generates revenue from exportation of hydro-electric power to its neighbors; Rwanda, Kenya, Tanzania and South Sudan. Reduction in power generation would cut off this source of income for the country.

\subsection{Health and Social Effects}

From a health standpoint, "[waterborne] diseases such as Diarrhea and Cholera are likely to increase with increased rainfall intensity and flooding, largely affecting areas with poor sanitation" (FCFA, 2016). Furthermore, FCFA asserts that higher temperatures and longer dry seasons are likely to increase Malaria incidence, which usually reaches its peak in the dry seasons when mosquitoes profusely breed in stagnant water pools all over the country.

Socially, Ugandans will have to cope with the discomfort of higher temperatures. The recent manifestation of intensified heatwaves during the January-February dry seasons goes to show what awaits the country in the near future. Certainly, heavy rains and floods will also inflict discomfort on the social lives of Ugandans, and coping mechanisms need to be devised.

\subsection{Spill-Over Economic Effects}

Uganda, which substantially relies on donor aid to fund a significant proportion of its budget, will certainly experience spill-over effects from climate change's damage on economic activities in its partner states. Donor aid to Uganda will most likely reduce, as donor countries will need more funds to cater for their own needs in the face of adversity. International trade will also be affected if trading partners experience substantial economic challenges rel

\section{Uganda's Efforts towards Adaptation to Climate Change}

Uganda has adeptly documented both climate change mitigation and adaptation mechanisms in its National Climate Change Policy.

"By signing and ratifying both the United Nations Framework Convention on Climate Change (UNFCCC) and the Kyoto Protocol, Uganda has committed to the adoption and implementation of policies and measures designed to mitigate climate change and adapt to its impacts... [and] Uganda's five-year National Development Plan (2015/16-2019/20) already recognizes that addressing the challenges of climate change is crucial to enhancing sustainable economic and social development" (Ministry of Water and Environment, 2015).

Uganda's National Climate Change Policy of 2015 predicts that climate change will cost Uganda $10 \%$ of its 
GDP by the year 2100 , and points to the fact that the country recognizes the need for action towards mitigating and adapting to climate change. The policy succinctly suggests several mitigation and adaptation strategies, including: promotion of highly adaptive crop and livestock breeds; promotion of agricultural diversification; development of insurance schemes; promotion of the development of energy conservation and efficiency projects in all sectors; among others.

Observable efforts towards mitigation of climate change have been considerably made, for example, striving to preserve wetlands, and combating deforestation. However, practical efforts towards adaptation to climate change are still scanty. Just like in many other sectors of Uganda and similar developing countries, the policy is available and apt, but its implementation is hardly existent.

\section{What More Needs to be Done?}

Notwithstanding other researchers' recommendations, the following, in my opinion, are the key actions that Uganda needs to take in order to effectively adapt to climate change.

The Government of Uganda should first and foremost work towards modernizing agriculture, to reduce the effects of drought. This includes promoting the use of effective contemporary farming methods like: crossbreeding; adopting drought-resistant crop and livestock breeds; using modern irrigation schemes; terracing in hilly areas and, greenhouse farming, among others. Some of these methods may not be applicable to rural homesteadagriculture due to the required scale and costs involved, but they are all applicable to commercial farming. The Government should equip commercial farmers with the knowledge and skills they need to practice modern farming methods. The rural population should also be sensitized about affordable modern farming methods like cross breeding, which would yield stronger drought resistant crop and animal strains.

The Government should promote adoption of drought insurance, which, currently is non-existent in Uganda. For this to work out, the Government needs to ensure that farmers are aptly sensitized about the risks presented by climate change, and the need for drought insurance. This will create demand for the insurance among farmers. The Government should then liaise with financial institutions in the private sector to ensure that the necessary insurance is provided. If a demand-driven market is created, profit seeking financial institutions will not hesitate to provide drought insurance.

As several researchers have suggested before, the Government of Uganda needs to diversify its economy to reduce its reliance on agriculture. More efforts need to be made towards growing the manufacturing and service sectors. These sectors, which are already established in the country and are less prone to climate change effects, would make the country's economy more immune to the adversity that may arise from climatic changes over time. Ugandans generally have the will to take on industrial projects but are constrained by lack of capital and necessary skills. The Government therefore needs to tailor its education system to contemporary industrial needs, in order to equip Ugandans with the necessary skills. Additionally, it should promote a stable financial environment to ensure that the population has adequate access to private sector credit, so as to obtain the necessary capital for investment.

In order to safeguard the transport sector from incapacitation due to heavy downpours, road construction and repairs going forward should be done with drainage systems that can contain large volumes of water. The Uganda National Roads Authority should determine the necessary drainage capacity basing on future rainfall predictions made by weather experts. This will ensure that business is undisrupted during rainy seasons, when the anticipated climate change takes effect.

Uganda's supply of fresh water from both surface (mainly lakes and rivers) and ground sources is adequate. However, the infrastructure required to tap the water is deficient. The Government should therefore invest in adequate infrastructure for country-wide piped water supply that is robust to climate change. This will diminish the population's dependence on rudimentary water sources that are prone to letdown in the face of climate change. It will also ensure that water can be transferred from areas of abundance to areas of scarcity, evening out the effect of geographical location. Furthermore, it would reduce the occurrence of water-borne diseases as people would have access to clean water for drinking and sanitation. Such a massive investment undoubtedly requires a lot of revenue, which the country currently does not possess. In the near future, however, Uganda anticipates receipt of above-normal proceeds from its budding oil industry. This investment is a worthwhile candidate for use of oil proceeds, since it will deliver both short term and long term socioeconomic benefits to Ugandans. Moreover, access to water is not a luxury, it is a basic need and a human right.

In order to moderate spill-over effects from climate change in donor countries, the Government of Uganda should seek to reduce dependence on donor aid by intensifying domestic revenue mobilization efforts. For this to play out, tax evasion and corruption in the country must be curtailed. Among other things, this calls for cooperation among government agencies. Transparency and information-sharing among government agencies can help reduce tax evasion. Additionally, full access to bank clients' information by the Uganda Revenue Authority (URA) would help curb tax evasion, as many Ugandans possess huge sums of money in banks, but hardly pay a dollar in tax. URA's full access to all necessary information (including banking records) for tax administration purposes is permitted in Uganda's law, but is not fully implemented. Several countries have empowered their tax 
administrators to access all banking records for tax administration purposes, and this has gone a long way in improving their tax collections. In Uganda's case, besides reduction of dependence on donor aid, extra resource mobilization would help fund other valuable undertakings, such as Malaria eradication initiatives. It should be noted however, that, URA lately attempted to access all bank clients' financial records in order to identify tax evaders, but it was blocked by other bureaucrats, who arguably had their own interests to protect. Nonetheless, it is still a viable channel for increment of domestic tax revenue, hence a standing recommendation. Perhaps, at a later date, it will be implemented.

The Government should put in place systems to ensure that the country gradually substitutes biomass and hydroelectric energy usage with oil energy usage. With careful consideration, this is very achievable in the medium term, bearing in mind the fact that Uganda now has a budding oil industry. Even though oil exploration negatively contributes to climate change, it will help ensure undisrupted continuity in the country's economic activities, when biomass and hydroelectric energy generation dwindles in the face of climate change. Besides, due to the presence of a free rider effect, other economies will continue to explore oil, so it wouldn't make much sense for Uganda to abstain alone.

On a lighter note, Ugandans need to adjust their way of life to adapt to higher temperatures in the dry seasons, for example, future home constructions should take into account issues like: the need for shade, usage of poor heat-conducting roofing materials, construction of wall ceilings under iron sheet roofs, incorporation of more ventilation in houses for better air circulation, etc. Where affordable, air conditioning should be considered. Conversely, houses in flood-prone areas should be constructed with elevated floors and stronger building materials, in order to withstand storms in the rainy seasons.

\section{Conclusion}

Uganda, like all other countries, is bound to experience adverse climatic changes in the near future, and it ought to adopt mitigation and adaptation mechanisms beforehand. It is anticipated that the country will experience several socioeconomic effects as a result of the changes. This paper has cited the key anticipated effects and expounded on them. These include: drought; agricultural destruction; transport encumbrances and destruction of lives and property due to floods; reduction in biomass and hydroelectric energy production; increase in waterborne diseases due to floods and poor sanitation; increase in Malaria incidence; social discomfort due to higher temperatures and, spill-over economic effects like reduced donor aid. All these events combined will adversely affect Uganda's economy if necessary action is not taken in time.

The necessary actions proposed in the paper are: modernization of agriculture; adoption of drought insurance schemes; economic diversification; construction of roads with adequate drainage; use of oil revenue to extend piped water supply to the country's entire population; intensification of domestic revenue mobilization to reduce dependence on donor aid; gradual substitution of biomass and hydroelectric energy usage with oil energy usage and, incorporation of climate change coping mechanisms in people's lifestyles.

From its National Climate Change Policy, it is clear that the Government of Uganda is well-aware of the impending effects of climate change, and has documented strategies to cope with the changes. However, practical efforts to implement these strategies have hardly been made. Action needs to be taken before it's too late, otherwise Uganda might experience the same disastrous effects that await those who bury their heads in the sand today, brushing off climate change as a fictitious story.

\section{References}

FCFA (Future Climate for Africa), 2016. Africa's Climate: Helping Decision-Makers Make Sense of Climate Information: Current and Projected Future Climate: Uganda Country Factsheet

http://www.futureclimateafrica.org/wp-content/uploads/2016/11/africas-climate-final-report-4nov16.pdf

Irish Aid, 2017. Uganda Climate Action Report for 2016

https://www.irishaid.ie/media/irishaid/allwebsitemedia/30whatwedo/climatechange/Uganda-Country-Climate-

Action-Reports-2016.pdf

Ministry of Water and Environment, 2015. Uganda National Climate Change Policy

http://www.mwe.go.ug/sites/default/files/library/National\%20Climate\%20Change\%20Policy\%20April\%202015 $\% 20$ final.pdf

Nsubuga N. W. Francis, Edith N. Namutebi, Masoud Nsubuga-Ssenfuma, 2014. Water Resources of Uganda: An Assessment and Review

http://file.scirp.org/pdf/JWARP_2014102716093775.pdf 